\title{
Research on the Slurry for Long-Distance Large-Diameter Pipe Jacking in Expansive Soil
}

\author{
Xian Yang $\left(\mathbb{D},{ }^{1,2}\right.$ Yang Liu, ${ }^{3}$ and Chao Yang ${ }^{3}$ \\ ${ }^{1}$ School of Resource and Safety Engineering, Central South University, Changsha 410083, China \\ ${ }^{2}$ School of Resource, Environment and Safety Engineering, Hunan University of Science and Technology, Xiangtan 411201, China \\ ${ }^{3}$ Hunan Provincial Key Laboratory of Shale Gas Resource Utilization, Hunan University of Science and Technology, \\ Xiangtan 411201, China \\ Correspondence should be addressed to Xian Yang; yangxjj@163.com
}

Received 12 June 2018; Accepted 27 August 2018; Published 14 October 2018

Academic Editor: Yonggui Chen

Copyright (c) 2018 Xian Yang et al. This is an open access article distributed under the Creative Commons Attribution License, which permits unrestricted use, distribution, and reproduction in any medium, provided the original work is properly cited.

\begin{abstract}
When the pipe jacking technology is applied in expansive formation, the soil around the pipe will easily absorb water from the slurry and expand to wrap up the pipe, producing an excessive pipe jacking force. A water-based slurry formula suitable for pipe jacking in expansive soil layer was proposed in this paper. Firstly, the key design points of pipe jacking slurry in expansive soil were put forward. Secondly, plant glue, potassium humate, Na-CMC, and graphite powder were chosen as treating agents to improve the slurry performance. The effect of addition levels of different treating agents on the funnel viscosity, filter loss, expansion ratio, friction coefficient and water dissociation rate of the slurry were tested. Thirdly, based on the results of single-factor tests, a waterbased slurry formula suitable for pipe jacking in expansive soil was obtained. Finally, the slurry formula was applied in a practical pipe jacking project in expansive formation, and the jacking force was controlled well in the whole jacking process. The new waterbased slurry is cheap and practical and has no pollution to environment. Furthermore, a simple and practical calculating method of the pipe jacking force was presented. The comparison of the calculated and measured pipe jacking force shows that the simple calculating method can estimate the jacking force well. Improving slurry performance to reduce jacking force in pipe jacking and predicting pipe jacking force accurately can help reducing the investment for counterforce wall and jacking system in pipe jacking engineering.
\end{abstract}

\section{Introduction}

The interaction between clay minerals and water leads to the expansibility, dispersion, thixotropy, plasticity, and impermeability of clay. Therefore, clay materials have been widely used in engineering fields, such as high-level radioactive waste disposal [1-3], dam clay core wall [4], drilling fluid [5], and so on. In the pipe jacking project, clay is always used to make thixotropic slurry for lubrication. Proper pipe jacking slurry can significantly reduce the pipe jacking force and reduce the investment of the reaction wall and relay stations. Especially in long-distance large-diameter pipe jacking engineering, excellent lubrication effect of slurry is essential. The poor lubrication effect will result in the increase of pipe jacking force, which will damage the reaction wall or the pipe
$[6,7]$. High-quality bentonite slurry with some treating agents was always used in pipe jacking in general formation [8]. However, when it comes to the expansive soil, the conventional slurry will lose the lubrication effect. The soil around the pipe will absorb the water from the slurry and expand to wrap up the pipe tightly, resulting in a sharp increase of pipe jacking force and the failure of the pipe jacking project.

At present, there are a lot of studies on the drilling slurry in the expansive formation. During drilling in expansive formations such as mudstone and shale, clay particles in the formation hydrated and dispersed into the drilling slurry, which not only increases the viscosity of the slurry, deteriorates the rheological properties, but also causes the expansion of the formation, shrink, or even collapse of the 
hole. Therefore, in the expansive formation, enhancing the inhibition of drilling slurry is most important. Inhibitory drilling fluid includes oil-based drilling fluid [9], syntheticbased drilling fluid [10], and water-based drilling fluid [11]. Oil-based drilling fluids and synthetic-based drilling fluids have good inhibition effect, but they cost highly and have adverse impact on environment. So, inhibitory water-based drilling fluids have been widely used. The most frequently used slurry includes calcium-treated mud [12] and potassium-based mud [11].

Good lubrication is the common requirement for pipe jacking slurry and drilling mud. In addition to lubrication, pipe jacking slurry also plays an important role in filling the gap between pipe and soil to support formation and reduce settlement. Drilling mud needs cooling bit and carrying the drilling debris by reciprocating cycle. From the above, it is seen that there are many different demands for the pipe jacking slurry and drilling mud. Therefore, there are similarities and differences as well between inhibitory drilling mud and pipe jacking slurry. We can learn from the design idea of inhibitory drilling mud to design pipe jacking slurry in expansive soil. At the same time, they should be considered the different functions to design their different characteristic parameters.

There are also many research studies on pipe jacking slurry, mainly focusing on the slurry formulation in general formation, the influence of lubricity and thixotropy of slurry on pipe jacking force [13] and so on. However, there are not many research studies on the formula of the pipe jacking water-based slurry in expansive soil. Wang et al. [14] indicated that the diesel base slurry was a good solution for clay hydration and dispersion in the expanding soil. Diesel base slurry has good lubricity and is conducive to formation stability, but the diesel can produce toxic aromatics that will badly affect the groundwater systems. In addition, large amount of slurry will be required for a long-distance largediameter pipe jacking project; this will lead to high cost when using oil base slurry.

In this paper, the key design points of pipe jacking slurry for pipe jacking in expansive soil were put forward by reference to the study on water-based drilling mud and the requirements for pipe jacking slurry in general formation. Several treatment agents were selected for single-factor test, and the effects of various treatment agents on the viscosity, water loss, expansion ratio, friction coefficient, and water dissociation rate were analyzed. Based on the results of single-factor test, a kind of water-based slurry suitable for pipe jacking in expansive soil was obtained, and the water base slurry gained good application effect in a practical project. Furthermore, a practical calculating method of the pipe jacking force was presented. Improving slurry performance to reduce jacking force in pipe jacking and predicting jacking force accurately can significantly reduce investment in pipe jacking engineering.

\section{Materials and Methods}

2.1. The Key Points of Slurry Formula Design. It is known that there are a large number of clay minerals in the expansive soil, especially the montmorillonite mineral. This will make the soil around the pipe absorb water from the slurry. The clay particles disperse into the gap between the pipe and the formation. Then the gap size will get smaller, or even the formation will collapse to wrap up the pipe tightly, leading to the failure of pipe jacking. For the pipe jacking in the expansive soil, decreasing the water penetration into the formation is very important, which can prevent the clay minerals dispersing into the gap between the pipe and the formation. Comprehensively, considering all kinds of performance requirements for the slurry in expansive soil, the following key points of slurry formula designs are put forward according to the requirements for the drilling mud in expansive formation and the pipe jacking slurry in general formation:

(1) Improve the inhibitory action of slurry. The addition of inhibitory additives into the slurry can reduce the dispersion of clay minerals and maintain the stability of the formation. During the shale drilling, the expansion ratio of shale should be generally controlled within $10 \%$, which can ensure the stability of the formation without sticking to the drill tools. Compared with the common core-drilling technology, pipe diameter in the pipe jacking is larger, and the gap between the pipe and the formation is larger as well. Also, the admissible expansion ratio in pipe jacking will be larger than that in the core-drilling technology. Therefore, the expansion ratio of formation is required to be controlled at $15 \%$ in this test.

(2) Improve the slurry viscosity. The higher the slurry viscosity, the lower the water penetration rate into the soil will be. The viscosity of pipe jacking slurry is always larger than the drilling mud. The funnel viscosity of thixotropic slurry is required to be ranged from $40 \mathrm{~s}$ to $65 \mathrm{~s}$ in general pipe jacking project. In this range, it can ensure the slurry's fluidity and fill the gap effectively but will not spread too much into the formation to result in surface deformation. In the expansive formation, the viscosity of the slurry should be relatively larger. In this test, the viscosity of slurry is required to be greater than $55 \mathrm{~s}$.

(3) Reduce the filter loss of slurry. The filter loss reducing agents can increase the thickness of the hydration film and increase the permeability resistance. Besides, they can improve the quality of filter cake obviously. The filter loss is always required to be less than $25 \mathrm{ml} / 30 \mathrm{~min}$ in the pipe jacking. In expansive soil formation, the filter loss should be smaller. In this test, it is required to be no more than $10 \mathrm{ml} / 30 \mathrm{~min}$.

(4) Reduce the water dissociation. After the slurry is prepared, the ratio of the water dissociated from the slurry to the volume of the original slurry within $24 \mathrm{~h}$ is called water dissociation rate. This parameter can reflect the stability of the slurry. The water dissociation rate of thixotropic slurry in the pipe jacking is required to be 0 . 
(5) Improve the slurry lubricity. The friction coefficient of water-based drilling mud tested by the extreme pressure lubrication instrument is commonly between 0.2 and 0.35 . The friction coefficient can be properly reduced when adding some lubricant agents. Considering the high requirements of longdistance large-diameter pipe jacking on slurry lubrication, the friction coefficient in this test is required to be controlled within 0.25 . (The materials contacted with the slurry in the test instrument are different from those in the practical project, so the friction coefficient obtained by the extreme pressure lubrication instrument cannot be directly used in the pipe jacking project).

2.2. Selection of Treating Agents. Considering the particularity of the expansive soil and the high requirement for the lubricity in pipe jacking, some corresponding treating agents must be added into the slurry system. In view of the economy and efficiency of the treatment agents, some materials were selected as follows.

2.2.1. Potassium Humate. Potassium humate is a high molecular compound aromatic hydroxy carboxylate and is soluble in water. Because the potassium humate contains many active functional groups such as the carboxyl group, the phenol hydroxyl group, the alcohol hydroxyl group, the carbonyl group, and the methoxy group, it can be strongly adsorbed by clay particles to form thin and elastic filter cake to reduce the filter loss. At the same time, because the special size of $\mathrm{k}^{+}$has, it can generate fixed effects on the crystal lattice of the clay mineral and result in inhibiting the clay hydration. The amount of potassium humate in the slurry is generally $2-3 \%$.

2.2.2. Plant Glue. Plant glue has good performances in tackifying and adjusting the slurry rheological property. The amount used in slurry is usually $2-3 \%$.

2.2.3. Low-Viscosity Na-CMC. It can help to form dense, firm, and low permeability filter cake on the surface of the formation to prevent the free water from slurry into the expansive soil formation. In addition to the filter loss reducing effect, the $\mathrm{Na}-\mathrm{CMC}$ has a certain performance in tackifying, and it is also good for the slurry stability. The general amount used in slurry is about $0.1 \%-0.2 \%$.

2.2.4. Graphite Powder. The graphite powder is selected as the lubricant in this test. Graphite powder can be firmly adsorbed on the pipe and the formation surface, thereby changing the friction state between the friction pairs and reducing the friction resistance. In addition to the good lubrication performance, the particles of the graphite powder can also enter the microcracks in the formation to block the cracks, which can prevent the free water from slurry into the soil and reduce the hydration of the clay minerals. The general addition amount of graphite powder is about $0.5 \%-1 \%$.

\subsection{Single Factor Test}

2.3.1. Test Instruments and Methods. The tests mainly aim at revealing the effect of different addition levels of different treating agents on the viscosity, filter loss, expansion rate, friction coefficient, and the water dissociation rate. Firstly, the base slurry was determined to be $8 \%$ bentonite powder $+0.3 \% \mathrm{NaCO}_{3}$. Then, a different additive was added into the base slurry separately. The variation rules of the viscosity, the filter loss rate, the expansion ratio, the friction coefficient, and the water dissociation rate of the several kinds of new slurry were studied. Figure 1 shows the test instruments.

(1) Swelling Tests. The silty clay encountered in an actual project was selected in the test. After drying, grinding, and sieving, the silty clay was made into mud powder. $12 \mathrm{~g}$ mud powder was loaded into the test tube and was compacted with $8 \mathrm{MPa}$ pressure to make a stand-by cylinder. Then the cylinder was put into the prepared slurry, and the linear expansion ratio of the cylinder was measured with expansion-testing equipment (Figure 1(a)).

(2) Filter Loss Tests. Slurry filter loss was tested by using the filter loss test instrument. The slurry was filled into the slurry cup, and the slurry cup was installed on the tee joint. Keeping the atmospheric pressure in the slurry cup at $0.69 \mathrm{MPa}$, the slurry's filtration volume in 30 minutes was measured, which was the filter loss (Figure 1(b)).

(3) Funnel Viscosity Tests. $500 \mathrm{ml}$ and $200 \mathrm{ml}$ slurry were measured by the steel measuring cylinder of Markov funnel viscometer and was poured into the funnel. Then, the time required for $500 \mathrm{ml}$ slurry to flow out was recorded, which was the slurry's funnel viscosity (Figure 1(c)).

(4) Lubricity Tests. The friction coefficient of the slurry was tested by using the extreme pressure lubrication instrument. The slurry was filled into the test cup, the motor was turned on, and the pressure was set to $16.95 \mathrm{~N} \cdot \mathrm{m}$. After the system had run for 5 minutes, the ammeter reading was recorded to calculate the slurry friction coefficient (Figure 1(d)).

(5) Stability Tests of the Slurry. After being prepared, the slurry was kept undisturbed for $24 \mathrm{~h}$. Then, the volume of water dissociated from the slurry was recorded to calculate the water dissociation rate of the slurry (Figure 1(e)).

2.3.2. Test Results and Analysis. The water dissociation rate of the base slurry is 0.05 . After adding some treating agents, the water dissociation rate is easy to be controlled to be 0 . So, the effect of treatment agents on the water dissociation rate will not be analyzed more. The effect of the treatment agents on the viscosity, the filter loss rate, the expansion rate, and the friction coefficient of slurry is analyzed as follows: 


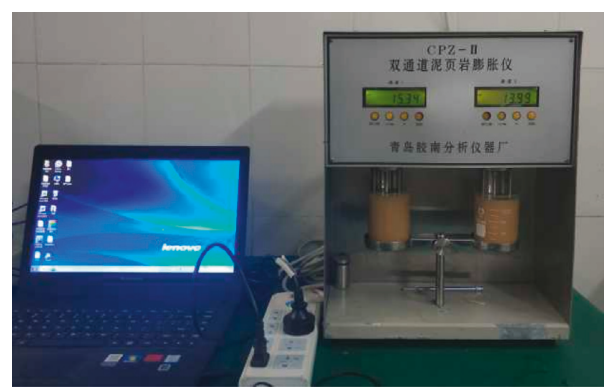

(a)

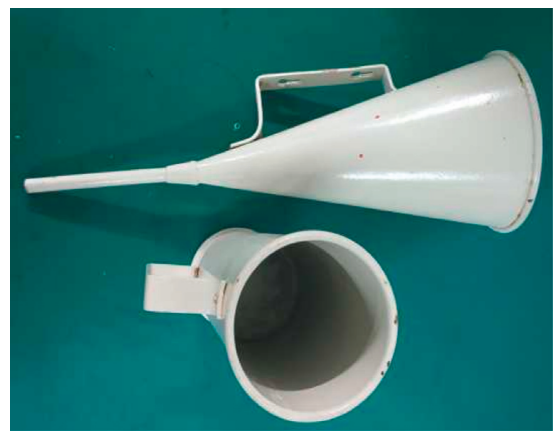

(c)

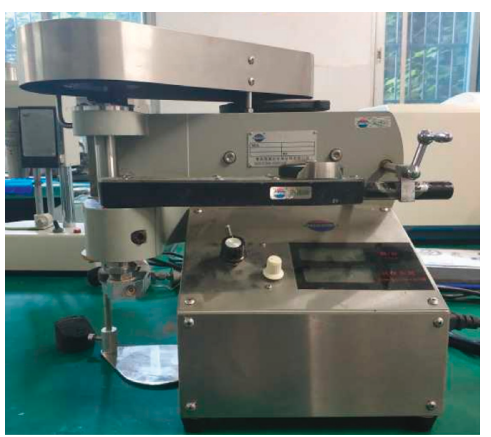

(d)

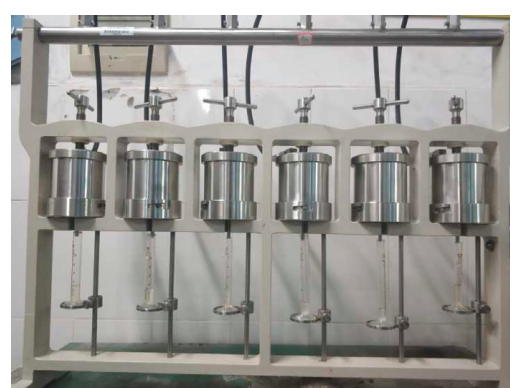

(b)

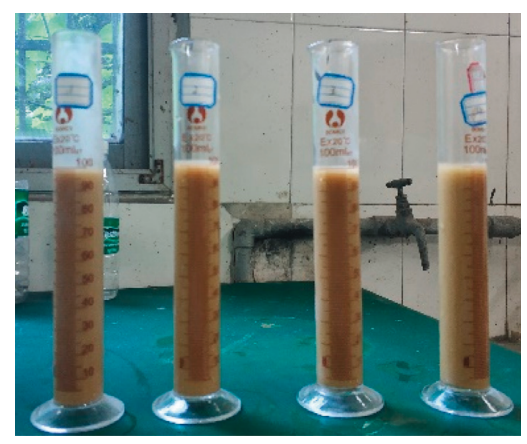

(e)

Figure 1: Tests of the slurry properties. (a) Swelling test. (b) Filter loss test. (c) Funnel viscosity test. (d) Lubricity test. (e) Stability test.

(1) The effect of plant glue on the slurry properties: as shown in Figure 2, with the increase of the plant glue, the funnel viscosity of the slurry increases, but the increasing tendency is getting smaller. The filter loss is not affected. Also, the expansion ratio of slurry decreases, but the decreasing tendency is not obvious. The plant glue has a slight beneficial effect on the slurry lubricity.

(2) The effect of potassium humate on the slurry properties: as we can see from Figure 3, the filter loss of the slurry is getting smaller with the increase of the potassium humate. And, the depressed tendency changes significantly when the addition amount of the potassium humate exceeds $2.5 \%$. Besides, the potassium humate has no effect on the slurry funnel viscosity. The expansion ratio decreases significantly with the increase of the potassium humate. And, it has a slight beneficial effect on the slurry lubricity.

(3) The effect of Na-CMC on the slurry properties: as shown in Figure 4, with the increase of Na-CMC, the filter loss of slurry is getting smaller, and the viscosity is getting larger. Besides, the expansion ratio declines slightly. The Na-CMC has no effect on the slurry lubricity.

(4) The effect of graphite powder on the slurry properties: as shown in Figure 5, the higher the amount of graphite powder, the better the slurry lubricity will be. However, the increase of graphite powder will have a slight adverse effect on the filter loss.

2.4. Slurry Formula Design and Performance Tests. The aim of the slurry formula is to meet the requirements when applying the long-distance large-diameter pipe jacking technology in the expansive formation. Based on the singlefactor tests, the additive amount of all kinds of treating agents could be selected. Considering the interaction between each single factor, the addition amount of all the treating agents had been adjusted. Finally, three kinds of slurry formulas had been proposed, and the performance tests of these three formulas were conducted. The slurry formulas were as follows:

base slurry $+2 \%$ potassium humate $+2 \%$ plant glue $+0.1 \% \mathrm{Na}-\mathrm{CMC}+0.75 \%$ graphite powder,

base slurry $+2.5 \%$ potassium humate $+2 \%$ plant glue $+0.15 \% \mathrm{Na}-\mathrm{CMC}+0.75 \%$ graphite powder,

base slurry $+3 \%$ potassium humate $+2.5 \%$ plant glue

$+0.2 \% \mathrm{Na}-\mathrm{CMC}+1 \%$ graphite powder.

In addition to the five tests that were the same as the single-factor tests, we also measured initial and final static shear-stress of the three kinds of slurry formulas by the sixspeed rotating viscometer (Figure 6). Static shear-stress refers to the strength of gel structure formed after the slurry is kept static for a while. The value of static shear-stress is determined by the number of structural chains in a unit volume of fluid and the strength of a single structural chain. The sequence of fluid structure gradually tends to be stable, and the structural development tends to be perfect, and the 

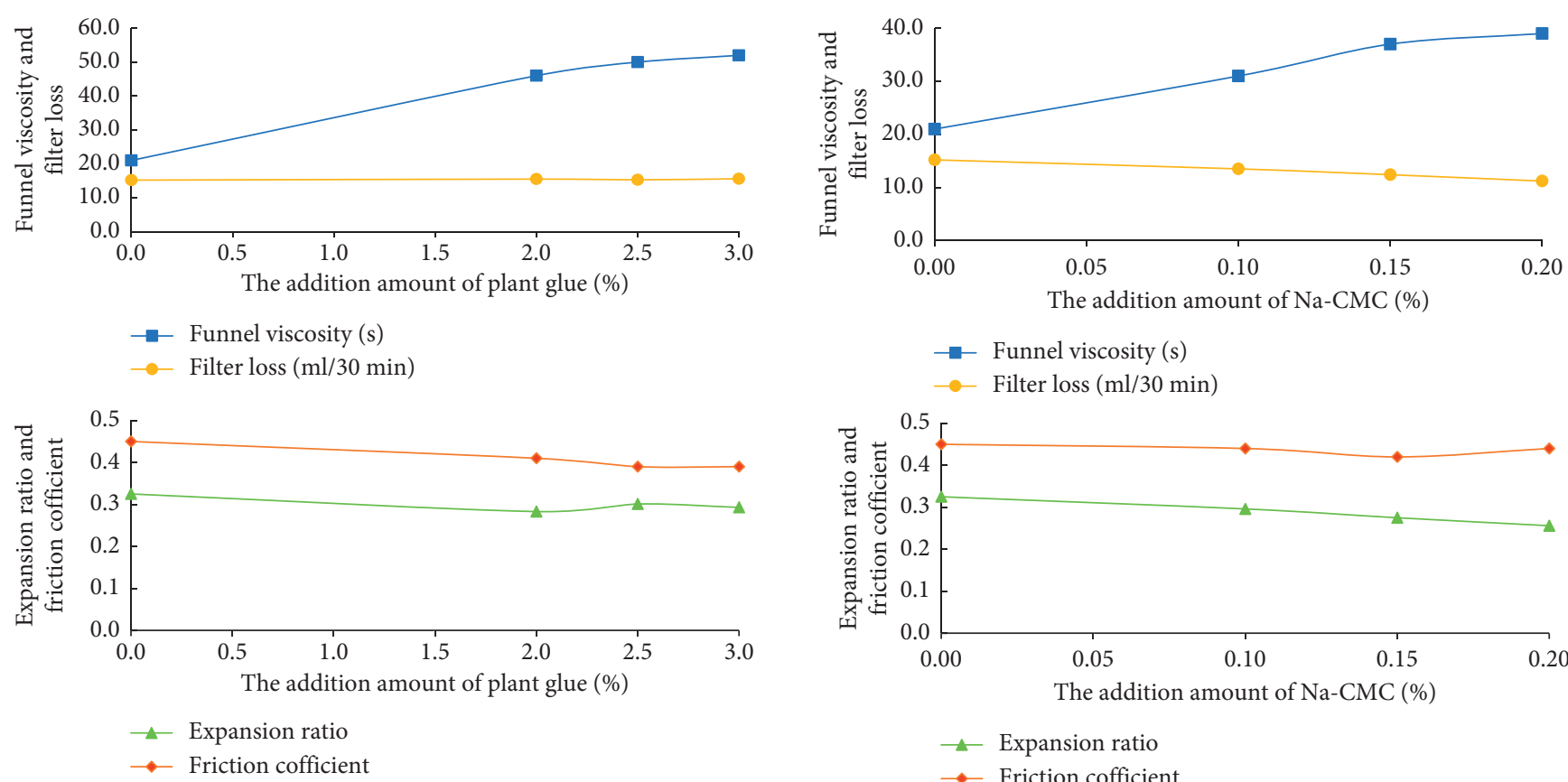

Figure 2: The effect of plant glue on the slurry properties.

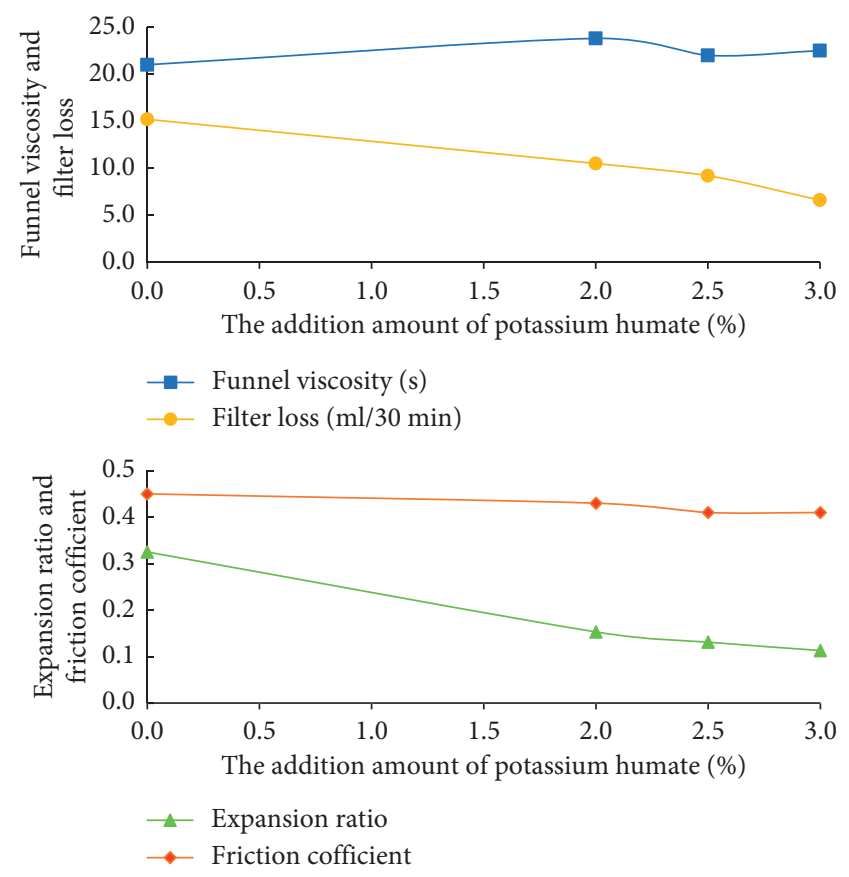

FIGURE 3: The effect of potassium humate on the slurry properties.

static shear-stress also increases. To measure the growth rate of gel strength, static shear-stress must be measured twice. According to the API standard, static shear-stress of 10 seconds and 10 minutes at rest is measured, which is called initial shear-stress and final shear-stress respectively. For thixotropic pipe jacking slurry, the greater static shear-stress means that when the pipe jacking stops and starts again, it needs greater pipe jacking force to overcome the network structure inside the slurry. Therefore, the jacking force is

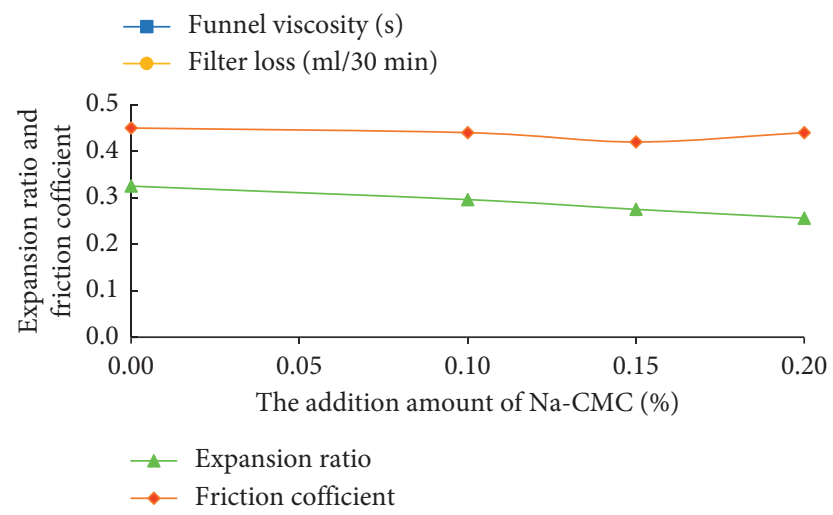

FIgURE 4: The effect of Na-CMC on the slurry properties.
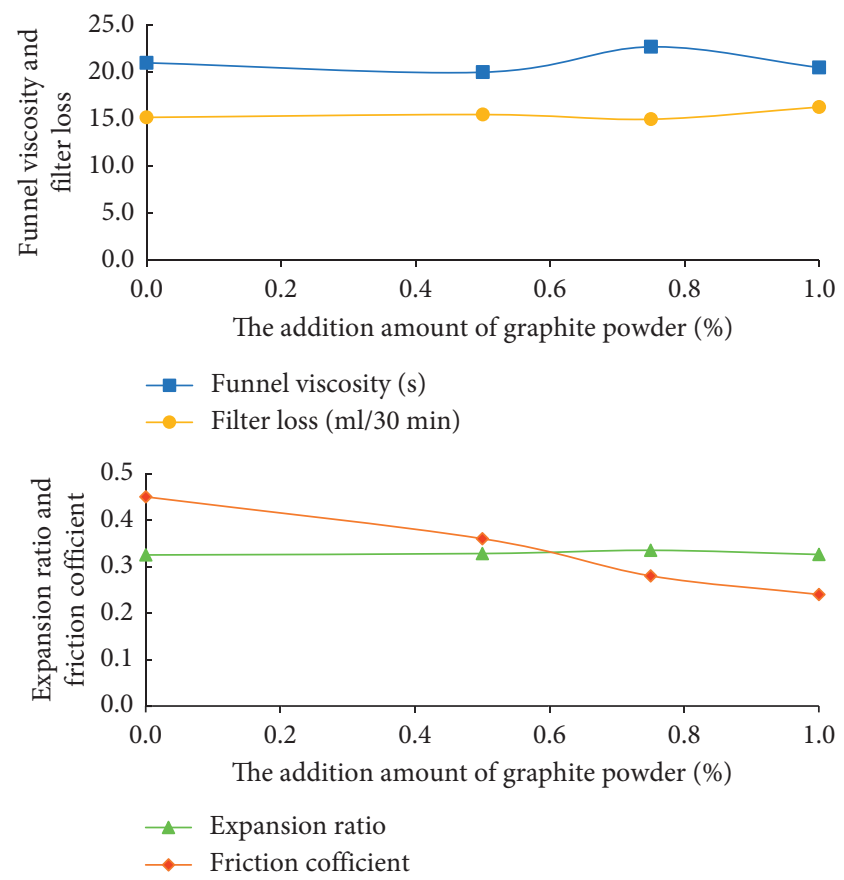

FIGURE 5: The effect of graphite powder on the slurry properties.

always larger than that in the normal pipe jacking state when the pipe is restarted. Too large shear-stress also causes higher pump pressure. However, the static shear-stress should not be too small. If the static shear-stress is too small, when the pipe jacking stops, the slurry fluidity is still too large, which is unfavorable for filling the gap between the pipe and formation and maintaining the formation stability. There is a great relationship between slurry shear-stress and viscosity. 


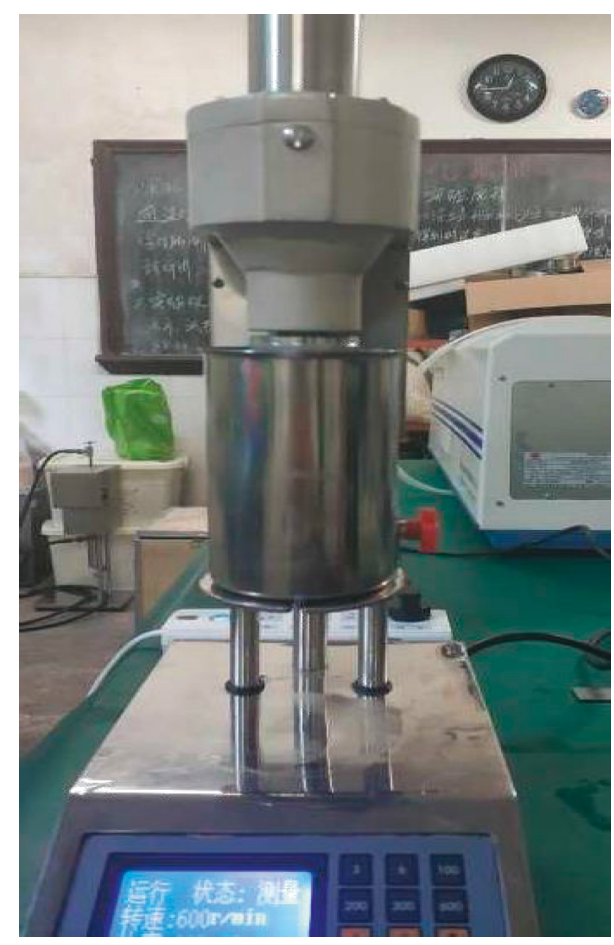

FIgURE 6: The six-speed rotating viscometer test.

Both Plant glue and Na-CMC can affect the static shearstress in the three kinds of slurry formula.

As shown in Table 1, both Formulas (2) and (3) can meet the design requirements mentioned in 2.1. So, the static shear-stress will be a key factor to select the better slurry formula. The static shear-stress of Formula (2) is more suitable, which is not too small or too large. Therefore, Formula (2) is selected when applying the long-distance large-diameter pipe jacking technology in an expansive soil formation.

\section{Results and Discussion}

\subsection{Overview of the Slurry Application in a Practical Pipe Jacking Project}

3.1.1. Geological Situation. It is a water supply pipeline along a road constructed by pipe jacking technology. In this project, the outer diameter of the steel pipe is $1500 \mathrm{~mm}$. The thickness of the pipe is $24 \mathrm{~mm}$. The total length of the pipeline is $492 \mathrm{~m}$. The overburden height is $3.2-4.8 \mathrm{~m}$. The underground water level is $6.4 \mathrm{~m}$. According to the geological survey report, the strata in this area from the top to the bottom are plain fill soil, clay, silty clay, silty clay sand inclusion layer, and gravel layer, respectively. The pipe jacking project is in the silty clay layer. The characteristics of the silty clay: brown red, hard plastic, high toughness, and visible cracks. The soil mass is $18.6 \mathrm{kN} / \mathrm{m}^{3}$, the cohesion is $24 \mathrm{kPa}$, and the internal friction angle is $18^{\circ}$. The compression coefficient is $0.13 \mathrm{MPa}^{-1}$, which belongs to medium compressibility soil. According to the expansion test, the average free expansion ratio of the soil is $51.4 \%$, but the largest free expansion ratio reaches $64.3 \%$. The potential of expansion is weak, and the potential of local expansion is medium.
3.1.2. The Pipe Jacking and Slurry System. The earth pressure balance jacking machine was used in this pipe jacking project. Four jacks with $2000 \mathrm{kN}$ oil cylinders were applied. The maximum bearing capacity of the reaction wall in the departure working shaft was $8000 \mathrm{kN}$. The pipes were made of steel tubes with strength grade Q235-B.

To reduce friction, slurry Formula (2) was selected to be used in this project. The synchronous grouting method was adopted at the rear of the driving machine to reduce the friction between pipe and formation in this project. In the front of each pipe, four grouting holes were arranged on a section (Figure 7). By using the BW-200 slurry pump, the lubrication slurry was injected into the gap between the pipe and the formation through the main pipe, the branch pipe, the ball valve, and the reserved grouting holes on the pipe. During the construction process, the grouting quantity was 1.5 times of the volume of the gap between the pipe and the formation, and the grouting pressure was $25-45 \mathrm{kPa}$.

According to the calculation result of pipe jacking force, a relay jacking ring had been designed in this project to provide enough pipe jacking force. But during the actual construction process, due to the good lubrication effect of slurry, the jacking force was smaller, so the jacking pipe construction was finally completed without using the relay jacking ring. Good lubrication results effectively simplified the operation procedure and reduced investment.

\subsection{Calculation and Monitoring of the Pipe Jacking Force}

3.2.1. Calculation Method of the Jacking Force. During the pipe jacking, the ideal situation is that the slurry forms a stable and closed sleeve at the outer surface of the pipe. In this case, the solid-liquid contact model can be used to calculate the jacking force. However, in the actual pipe jacking process, it is often difficult to achieve complete solidliquid contact and to avoid the direct contact between the pipe and the soil. Besides, due to the existence of the gap between the pipe and the formation, if the soil is stable and does not collapse, the complete pipe-soil contact will not exist, too. Therefore, the actual pipe jacking contact should be a complex contact mode combining partial pipe-soil contact with partial pipe-slurry-soil contact.

As found in some domestic and foreign relevant specifications, complete pipe-soil contact model was mostly used to calculate the pipe jacking force. In this model, the gap between the pipe and the formation is not considered, and it indicates that the jacking force is equal to the frictional resistance caused by the soil pressure on the pipe. And many monitoring results showed that the jacking force is much smaller than the jacking force calculated by this model. If that the pipe was completely covered by slurry sleeve in the process of pipe jacking, Ye et al. [15] proposed a solid-liquid contact model to calculate the pipe jacking force. Zhang et al. [16] divided the contact outside the pipe into the pipe-soil contact and the pipe-slurry-soil contact to calculate the contact friction force of the two parts, respectively. However, there is an implicit condition in Zhang's model [16]. In Zhang's model [16], the stratum is a completely self-stability 
TABLE 1: The properties of the slurry.

\begin{tabular}{|c|c|c|c|c|c|c|c|}
\hline $\begin{array}{l}\text { Slurry } \\
\text { formulas }\end{array}$ & $\begin{array}{c}\text { Funnel } \\
\text { viscosity (s) }\end{array}$ & $\begin{array}{c}\text { Initial static shear- } \\
\text { stress }(\mathrm{kPa})\end{array}$ & $\begin{array}{c}\text { Final static shear- } \\
\text { stress }(\mathrm{kPa})\end{array}$ & $\begin{array}{c}\text { Filter loss } \\
(\mathrm{ml} / 30 \mathrm{~min})\end{array}$ & $\begin{array}{l}\text { Expansion } \\
\text { ratio }(\%)\end{array}$ & $\begin{array}{c}\text { Friction } \\
\text { coefficient }\end{array}$ & $\begin{array}{c}\text { Water } \\
\text { dissociation rate }\end{array}$ \\
\hline Base slurry & 21 & 5.18 & 6.5 & 15.2 & 32.5 & 0.45 & 0.05 \\
\hline $\begin{array}{l}\text { Formula } \\
\text { (1) }\end{array}$ & 52 & 5.66 & 7.98 & 8.6 & 12.5 & 0.28 & 0 \\
\hline $\begin{array}{l}\text { Formula } \\
\text { (2) }\end{array}$ & 57 & 5.78 & 8.24 & 7.2 & 11.8 & 0.25 & 0 \\
\hline $\begin{array}{l}\text { Formula } \\
\text { (3) }\end{array}$ & 62 & 6.14 & 9.65 & 7.1 & 11.3 & 0.23 & 0 \\
\hline
\end{tabular}

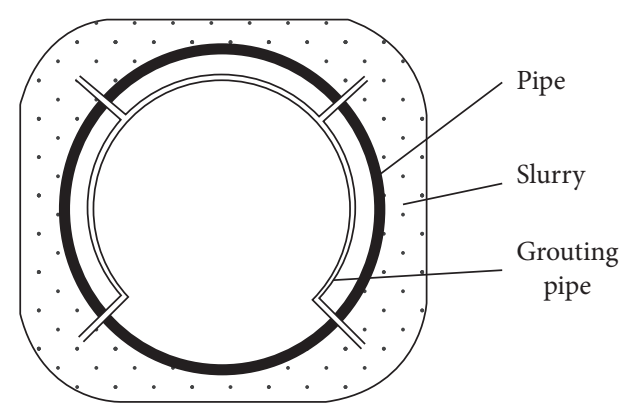

Figure 7: The schematic diagram of grouting in pipe jacking.

system, that is, there is no earth pressure on the pipe absolutely. Therefore, when the friction coefficient was supposed to be 0.5 , the calculated jacking force was in good agreement with the measured jacking force in Zhang's research [16]. However, according to the test results of the slurry friction coefficient tests, the friction coefficient is generally less than 0.5 , which indicates that when earth pressure is not considered, the calculated jacking force by using Zhang's method [16] is relatively smaller.

Combining with Zhang's research [16] and Terzaghi loose earth theory [17], a practical calculating method for the pipe jacking force is presented based on the pipe-soil and pipe-slurry-soil combinative contact model (Figure 8). According to angle calculation formula in Persson contact model, it is concluded that the pipe-soil contact angle can be approximately $180^{\circ}$, that is, the upper part of the contact model is the pipe-slurry-soil contact, and the lower part is the pipe-soil contact [16].

When calculating the jacking force of the upper part, it is considered that the slurry in the gap between the pipe and the formation only transmits hydrostatic pressure. The contact friction per unit length is calculated as follows:

$$
f_{\text {pipe-slurry }}=\frac{\left(p_{\mathrm{m}} \mu_{1}+c_{1}\right) \pi D}{2},
$$

where $f_{\text {pipe-slurry }}$ is the friction per unit length between the pipe and slurry, $\mathrm{kN} . p_{\mathrm{m}}$ is the slurry pressure outside the pipe, $\mathrm{kPa}$. Usually, the value is supposed to be equal to the hydrostatic pressure on the pipe plus $20 \mathrm{kPa}$. $D$ is the external diameter of pipe, m. $\mu_{1}$ is the friction coefficient between the pipe and the slurry. $c_{1}$ is the cohesion between the pipe and the slurry, $\mathrm{kPa}$, which can be ignored due to the good lubrication performance of the slurry.

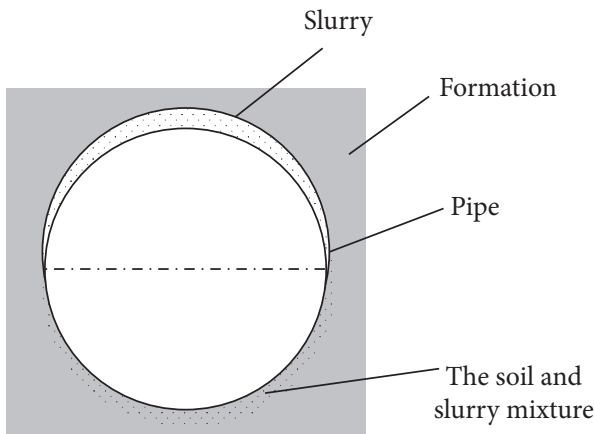

FIgURE 8: The schematic of diagram the pipe-soil and pipe-slurry combinative contact model [16].

When calculating the jacking force of the lower part, it is considered that the steel pipe gravity and the soil pressure on the pipe are loaded onto the soil under the steel pipe. Terzaghi loose earth theory [17] is used to calculate the earth pressure on the pipe (Figure 9):

$$
\sigma_{\mathrm{z}}=\frac{B(\gamma-c / B)}{k_{0} \tan \varphi}\left(1-e^{-k_{0} \tan \varphi^{H / B}}\right),
$$

where $\sigma_{\mathrm{z}}$ is the earth pressure on the pipe, $\mathrm{kPa} . k_{0}$ is the Rankine active earth pressure coefficient. $c$ is the cohesion of soil, $\mathrm{kPa} . B$ is half of the width of the soil damage line, m. $\gamma$ is the soil mass, $\mathrm{kN} / \mathrm{m}^{3} . \varphi$ is the internal friction angle of soil, . $H$ is the buried depth, m. Calculation formula of pipe-soil friction is

$$
f_{\text {pipe-soil }}=\left(\frac{\sigma_{\mathrm{z}} \pi D}{2}+G\right) \mu_{2}+\frac{c_{2} \pi D}{2},
$$

where $f_{\text {pipe-soil }}$ is the friction per unit length between the pipe and soil, $\mathrm{kN}$. $G$ is the pipe weight per unit length, $\mathrm{kN}$. $\mu_{2}$ is the friction coefficient between the pipe and slurry-soil mixture. $c_{2}$ is the cohesion between the pipe and slurry-soil mixture, $\mathrm{kPa}$. Because graphite powder is mixed into the slurry, the lubricity of the slurry-soil mixture is good, so the cohesive force is ignored.

Therefore, the calculation formula of the pipe jacking force per unit length is as follows:

$$
f=f_{\text {pipe-slurry }}+f_{\text {pipe-soil }},
$$

where $f$ is the whole friction per unit length, $\mathrm{kN}$.

The friction coefficient is usually in the range of $0.07-$ 0.10 [7]. And, it is related to the grouting amount, grouting 


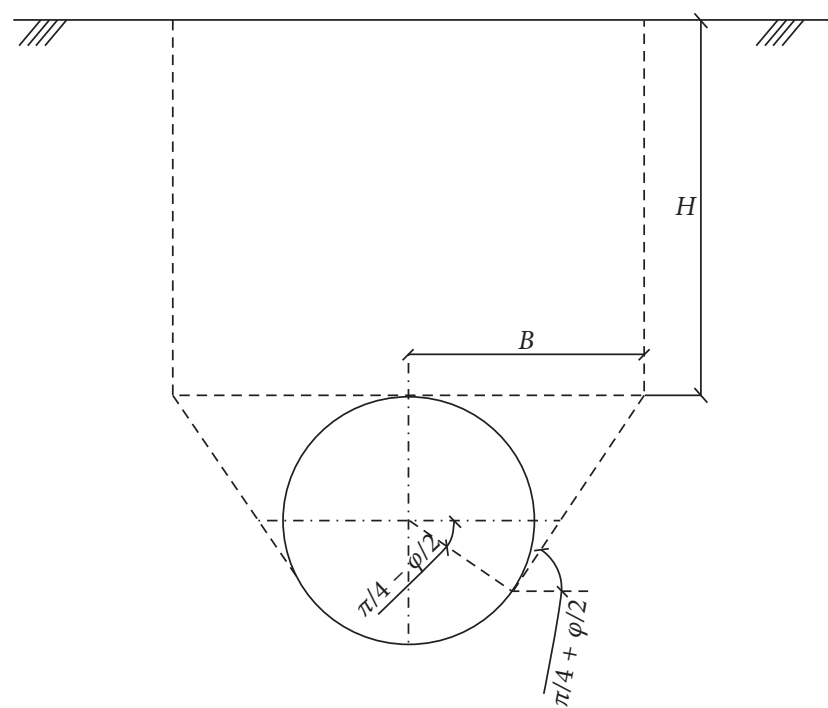

Figure 9: The schematic diagram of the Terzaghi loose earth theory [17].

uniformity, slurry sleeve integrity, etc. It is also found that the lower value will be taken when the lubrication effect is good. On the contrary, the higher value will be taken, but usually the value will be no more than 0.2 . Besides, the friction coefficient is approximately equal to $\tan \varphi$ without grouting [7]. Therefore, in this calculation, the friction coefficient of the pipe-slurry contact part is set as 0.1 . In the pipe-soil contact, there is some slurry mixed with the soil, so the friction coefficient of the mixture is approximately set as follows:

$$
\mu_{2}=\frac{(0.2+\tan \varphi)}{2} .
$$

The average overburden height is $4 \mathrm{~m}$. In this pipe jacking project, the calculated jacking force per unit length is $16.56 \mathrm{kN}$.

3.2.2. Comparison and Discussion. The jacking force is monitored throughout the whole jacking process. Figure 10 shows the monitoring results of the initial $100 \mathrm{~m}$ construction in the pipe jacking project. It is found that the measured jacking force is about $10 \%$ smaller than the calculated jacking force. At the initial stage of the jacking process and the pipe jacking section between 40 and $50 \mathrm{~m}$ (the pipe jacking was paused and restarted during this period), the jacking force is significantly larger. The main reason is that in these two construction sections, the slurry is changed from the liquid state to the gelatinous state after keeping static for some time, and the static shear-stress increased. When the pipe jacking construction is restarted, it is required to overcome the static shear-stress of the slurry, resulting in an increase of the pipe jacking force.

The monitoring results showed that the selection of slurry Formula (2) had provided good lubrication for the long-distance large-diameter pipe jacking in the expansive soil. Under normal lubrication condition, the pipe jacking

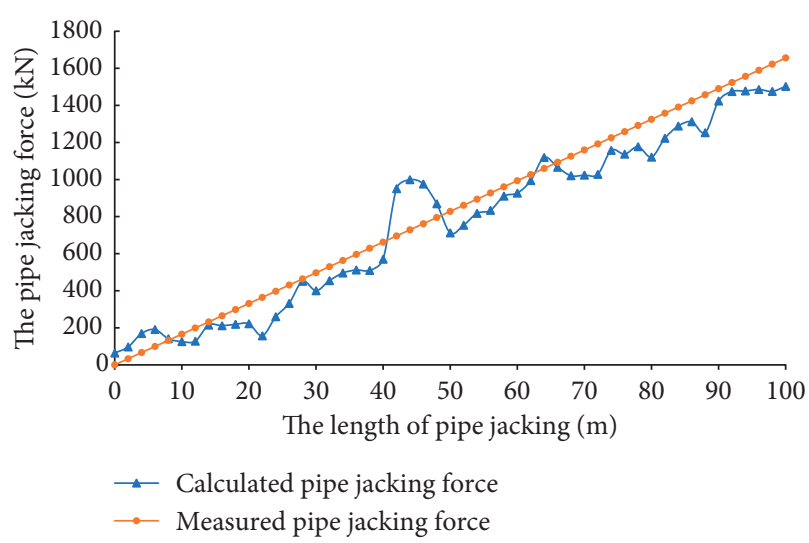

FIgURE 10: The calculated and measured pipe jacking force.

force had been controlled well. Meanwhile, the actual contact situation of pipe jacking was fully considered in the pipe jacking calculated method. So, the more accurate prediction of pipe jacking force had been obtained with the method.

\section{Conclusions}

(1) Combined with the requirements for the pipe jacking slurry in general formation and the drilling mud in expansive formation, the key design points of slurry for the long-distance large-diameter pipe jacking project in expansive soil were put forward.

(2) Based on the laboratory tests, the thixotropic slurry properties change rules were obtained, as the addition amount of plant glue, potassium humate, $\mathrm{Na}$ $\mathrm{CMC}$, and graphite powder changed. According to the results of single-factor tests, three kinds of inhibitive slurry formulas were prepared, and their properties were comprehensively tested. Both Formulas (2) and (3) could fully meet the requirements for the long-distance large-diameter pipe jacking project in the expansion formation. Because the static shear-stress of Formula (2) was more suitable, the Formula (2) was selected to be used in a practical project. The monitoring results showed that the slurry Formula (2) had a great lubrication effect in the expansive formation.

(3) Combined with the Terzaghi loose earth theory and the actual contact situation of pipe jacking, a practical calculated method of the pipe jacking force was presented. The calculated jacking force per unit length was $16.56 \mathrm{kN}$ according to the new method. And the actual jacking force was about 10\% smaller than the calculated pipe jacking force. It proved that the new method could accurately predict the pipe jacking force.

\section{Data Availability}

The numerical data used to support the findings of this study are included within the article. All the lab test data and calculation results data used to support the findings of this study are also available. 


\section{Conflicts of Interest}

The authors declare that they have no conflicts of interest.

\section{Acknowledgments}

The authors are grateful to the National Natural Science Foundation of China (41702323 and 51608192), the Natural Science Foundation of Hunan Province (2016JJ3062), and the Postdoctoral Science Foundation of Central South University (160320001 and 140050007).

\section{References}

[1] Y. G. Chen, L. Y. Jia, Q. Li, W. M. Ye, Y. J. Cui, and B. Chen, "Swelling deformation of compacted GMZ bentonite experiencing chemical cycles of sodium-calcium exchange and salinization-desalinization effect," Applied Clay Science, vol. 141, pp. 55-63, 2017.

[2] Y. G. Chen, C. M. Zhu, W. M. Ye, Y. J. Cui, and Q. Wang, "Swelling pressure and hydraulic conductivity of compacted GMZ01bentonite under salinization-desalinization cycle conditions," Applied Clay Science, vol. 114, pp. 454-460, 2015.

[3] Y. G. Chen, Y. J. Cui, A. M. Tang, Q. Wang, and W. M. Ye, "A preliminary study on hydraulic resistance of bentonite/hostrock seal interface," Geotechnique, vol. 64, no. 12, pp. 997$1002,2014$.

[4] K. D. Liu, "Research on structure force of clay core wall stone slag dam," Applied Mechanics and Materials, vol. 394, pp. 376-380, 2013.

[5] C. G. Struchtemeyer, J. P. Davis, and M. S. Elshahed, "Influence of the drilling mud formulation process on the bacterial communities in thermogenic natural gas wells of the barnett shale," Applied and Environmental Microbiology, vol. 77, no. 14, pp. 4744-4753, 2011.

[6] J. Yen and K. Shou, "Numerical simulation for the estimation the jacking force of pipe jacking," Tunnelling and Underground Space Technology, vol. 49, pp. 218-229, 2015.

[7] A. L. Pellet Beaucour and R. Kastner, "Experimental and analytical study of friction forces during microtunneling operations," Tunnelling and Underground Space Technology Incorporating Trenchless Technology Research, vol. 17, no. 1, pp. 83-97, 2002.

[8] C. C. Reilly and T. L. L. Orr, "Physical modelling of the effect of lubricants in pipe jacking," Tunnelling and Underground Space Technology, vol. 63, pp. 44-53, 2017.

[9] T. Elshehabi and I. Bilgesu, "Impact of drilling with oil based mud on well control in horizontal shale gas wells," in Proceedings of SPE Eastern Regional Meeting, Morgantown, WV, USA, October 2015.

[10] M. S. Zazarli Shah, A. Sauki, W. Z. W. Bakar, N. A. Ghazali, and A. Azizi, "Drilling fluid design for shale gas drilling," Advanced Materials Research, vol. 1113, pp. 617-624, 2015.

[11] A. Aftab, A. R. Ismail, and Z. H. Ibupoto, "Enhancing the rheological properties and shale inhibition behavior of waterbased mud using nanosilica, multi-walled carbon nanotube, and graphene nanoplatelet," Egyptian Journal of Petroleum, vol. 26, no. 2, pp. 291-299, 2016.

[12] A. Babajide, O. Adebowale, F. Adesina et al., "Effects of temperature and pressure on shale cuttings dispersion in water based mud WBM using NACL, CACL2, KCL salts as primary inhibiting agents and polymer XCD xanthan gum as secondary inhibiting agent," in Proceedings of SPE Nigeria
International Conference and Exhibition, Lagos, Nigeria, August 2016.

[13] H. Shimada, S. Khazaei, and K. Matsui, "Small diameter tunnel excavation method using slurry pipe-jacking," Geotechnical and Geological Engineering, vol. 22, no. 2, pp. 161186, 2004.

[14] M. Y. Wang, H. Li, and B. J. Geng, "Analysis on the practical application of pipe engineering in expansive soil," Shan Dong Water Resource, vol. 8, pp. 32-33, 2009, in Chinese.

[15] Y. C. Ye, L. M. Peng, W. C. Yang et al., "Calculation of jacking force for pipe-jacking considering mud slurry thixotropy," Chinese Journal of Geo-technical Engineering, vol. 37, pp. 1653-1659, 2015, in Chinese.

[16] P. Zhang, B. S. Ma, C. Zeng et al., "Numerical model for jacking force based on pipe-soil contact characteristics," Chinese Journal of Geo-technical Engineering, vol. 39, pp. 244-249, 2017, in Chinese.

[17] K. Terzaghi, Theoretical Soil Mechanics, John-Wiley and Sons, Hoboken, NJ, USA, 1943. 


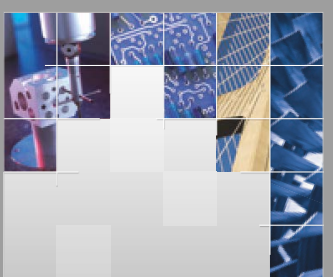

\section{Enfincering}
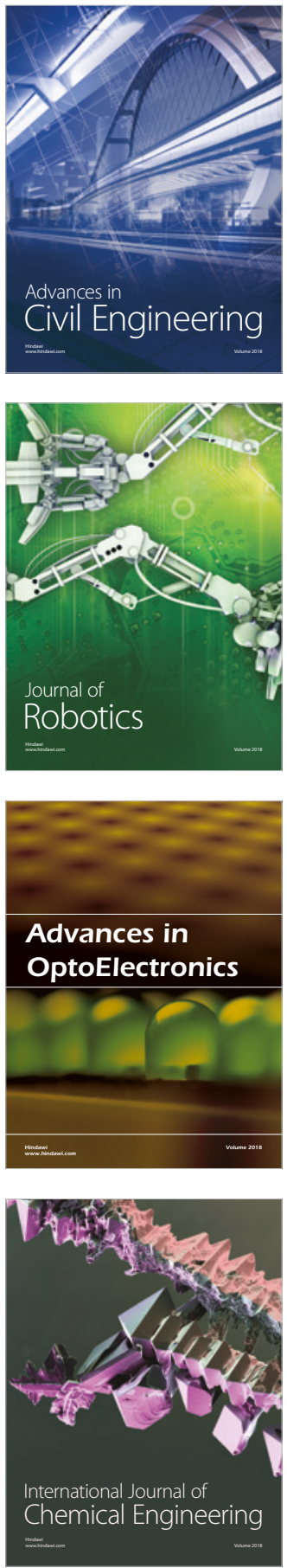

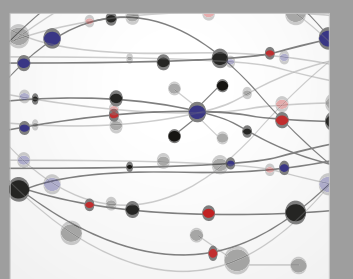

\section{Rotating \\ Machinery}

The Scientific World Journal

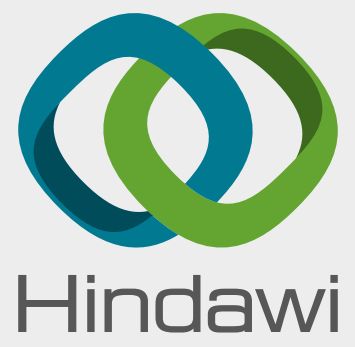

Submit your manuscripts at

www.hindawi.com
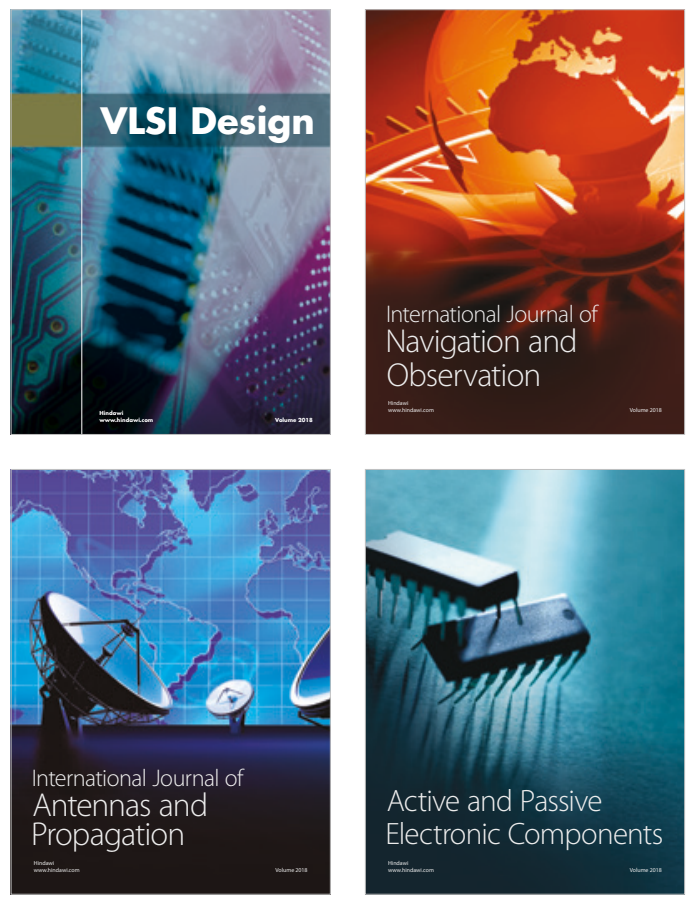
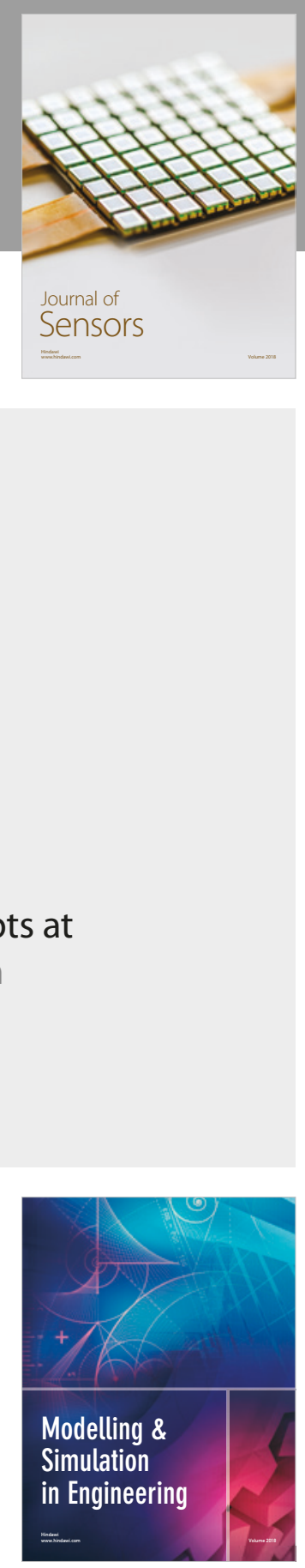

\section{Advances \\ Multimedia}
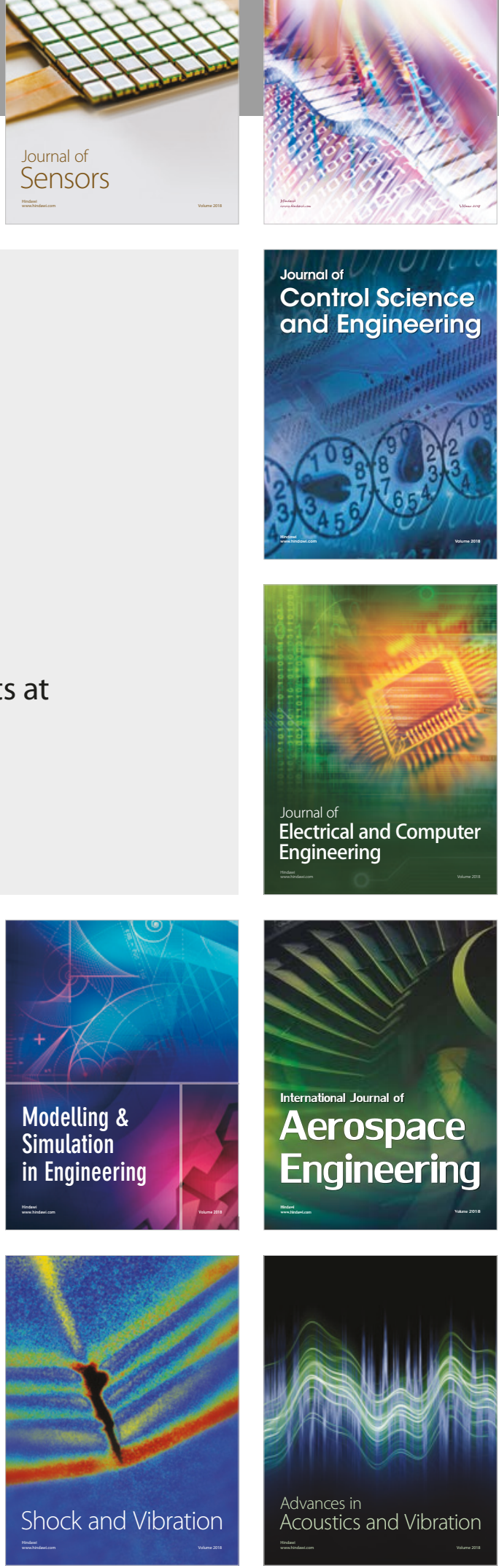